\title{
Detailed Analysis of Rare Causes of Secondary Duodenitis in Patients Diagnosed with Endoscopic Duodenitis: A Cross-Sectional Study from a Tertiary Referral Center
}

\author{
๑ Atilla Bulur, ๑ Uguray Payam Hacisalihoglu* \\ Nazilli State Hospital, Clinic of Gastroenterology, Aydin, Turkey \\ *Yeni Yuzyil University Faculty of Medicine, Gaziosmanpasa Hospital, Clinic of Pathology, Istanbul, Turkey
}

\section{Abstract}

Aim: Findings compatible with duodenitis are not rare in patients who have undergone endoscopy. Although the final histopathological diagnoses in most of these cases are chronic primary non-specific duodenitis, less commonly, there are also diseases that cause secondary duodenitis, too. We aimed to examine the causes of secondary duodenitis in our patients in detail.

Methods: Upper gastrointestinal endoscopic procedures of 3.776 adult patients performed for various reasons in our endoscopy unit (Istanbul Yeni Yuzyıl University, Medical Faculty, Gaziosmanpasa Hospital, Department of Gastroenterology) between 2017 and 2021 were reviewed retrospectively by scanning the hospital automation system. The demographic, clinical, endoscopic, and histopathological features of the patients who underwent endoscopic biopsies with a prediagnosis of duodenitis were examined.

Results: Biopsies with a pre-diagnosis of duodenitis were performed on 231 (6.12\%) of 3776 adult patients during the endoscopic procedures. The mean age of the patients was 42.03 years (18-89 years); $42.4 \%$ were males and $57.6 \%$ were female. The most common symptoms/signs of the patients were dyspepsia (45\%), chronic diarrhea (38\%), and iron deficiency anemia (34\%), respectively. The two main histological diagnoses were primary non-specific duodenitis (58.44\%) and celiac disease (29.87\%). In the remaining cases, various causes of secondary duodenitis such as graft versus host disease, eosinophilic duodenitis, Brunner's gland adenoma, polyps, giardiasis, Crohn's disease, cytomegalovirus duodenitis, and amyloidosis were detected.

Conclusion: Although the most common etiology of duodenitis we encountered in our study was primary non-specific duodenitis, a considerable number, and variety of other etiologies of secondary duodenitis were also detected. Among many causes of secondary duodenitis, celiac disease should be kept in mind especially in female patients with younger age, presenting with dyspepsia.

Keywords: Duodenitis, endoscopy, histopathology

\section{Introduction}

Duodenitis occurs as a result of epithelial damage and inflammation of the duodenal mucosa. The pathognomonic diagnosis of duodenitis is achieved through histopathological examination of biopsies obtained from abnormal appearing duodenal mucosa samples composed of uniform, multifocal, superficial duodenal erosions, mucosal edema, and hyperemia, during endoscopic examination. Duodenitis is divided into acute and chronic in terms of clinical course. Chronic duodenitis is divided into primary (non-specific duodenitis:
NSD) and secondary (specific) duodenitis. Histological findings with duodenal mucosal damage as a result of prolonged exposure to increased gastric secretion are also called peptic duodenitis or chronic NSD. Duodenitis may also occur secondary to increased acid secretion, increased bile reflux, viral, bacterial, fungal, and parasitic infections, chemical agents, radiation, drugs i.e. non-steroidal antiinflammatory drugs, alcohol, allergens, and autoimmune diseases (1-3).

In some studies, it was stated that gastric pathologies caused by $H$. pylori may induce NSD. In another study, it

Address for Correspondence: Atilla Bulur, Nazilli State Hospital, Clinic of Gastroenterology, Aydin, Turkey 
was reported that intestinal metaplasia may contribute to NSD. In another study, the authors stated that duodenal ulcer disease may be one of the clinical stages of NSD (4-7). Non-peptic secondary duodenitis occurs in the younger age group with distal duodenal involvement as panduodenitis or postbulbitis $(8,9)$. There are many different local or systemic causes of secondary duodenitis such as inflammatory bowel diseases (IBD), celiac disease (CD; gluten enteropathy), eosinophilic gastroenteritis, acute and chronic infections [tuberculosis, giardiasis, cytomegalovirus (CMV), HSV, HIV, candidiasis etc], vasculitis (Behcet's disease, Henoch-Schönlein purpura etc) and autoimmune diseases. Among these, CD is the most common cause of secondary duodenitis.

We investigated the histopathological diagnoses of the biopsies taken from abnormal mucosal areas in the second part of the duodenum, which were endoscopically diagnosed as duodenitis, with giving more emphasis on secondary nonspecific causes of duodenitis.

In clinical practice, NSD and CD come to mind when endoscopic duodenitis is mentioned. However, there are many secondary causes of duodenitis other than $C D$. We found that few studies have been conducted on secondary causes of duodenitis in the literature. Therefore, in the present study, we aimed to investigate the causes of secondary duodenitis in our clinic.

\section{Methods}

\section{Study Design}

The present study was approved by the Istanbul Yeni Yuzyil University of Medicinal Ethics Committee (number; 13.08.2020/031) and conducted between from September 2017 to February 2021 in accordance with the Declaration of Helsinki. A consent form was filled out by all participants.

We investigated upper gastrointestinal endoscopic (UGE) procedures of 3.776 adult patients performed for various reasons in the endoscopy unit of a tertiary referral center (Istanbul Yeni Yuzyil University, Medical Faculty, Gaziosmanpasa Hospital, Department of Gastroenterology) between 2017 and 2021 were retrospectively screened.

The demographic data, main complaints, UGE findings, and histopathological diagnoses were obtained from the hospital automation system.

The patients that had biopsies taken from the second part of the duodenum with a pre-diagnosis of duodenitis were included. Lesions in the duodenal bulbus and stomach such as ulcer, erosion, gastritis, bulbitis were excluded and only the lesions localized in the second part of the duodenum were examined.

\section{Endoscopic and Histopathologic Procedure}

UGE examinations were performed with a Fujinon EG 590 WR video gastroscopy device (Japan) and forcepsguided biopsy. For histological examination, biopsy specimens fixed with 10\% formalin were obtained after routine tissue processing. Serial sections of $4 \mu \mathrm{m}$ were prepared from the specimens embedded in paraffin blocks. Hematoxylin \& Eosin stain was used for histological examination of the deparaffinized tissue sections. AntiCD3 immunohistochemical antibody was applied to biopsy materials to detect intraepithelial lymphocytosis, (DAKO, Clone F.7.38, USA). In histopathological evaluation, biopsies were evaluated mainly in terms of intraepithelial lymphocytosis (>40 lymphocytes per 100 enterocytes), crypt hyperplasia, and villous atrophy and divided into 5 different categories according to the classification defined by Marsh and modified by Oberhuber (Modified Marsh Classification) (10).

\section{Statistical Analysis}

The research data were worked up into Excel sheets. Statistical Package for the Social Sciences Version 23.0 (SPSS 23.0 Chicago, USA) for Windows was used for statistical analysis. The defining statistics are presented as numbers and percentages for categorical variables, and a mean, standard deviation (SD), and median are included for numeric variables. The categorized groups were compared using the chi-square test. A statistical significance level of alpha was accepted as $p<0.05$.

\section{Results}

UGE procedures performed on 3.776 adult patients in the gastroenterology endoscopy unit of our hospital between 2017 and 2021 were retrospectively screened. In 231 of these procedures (6.12\%), biopsies were taken from the duodenum via forceps with a preliminary diagnosis of duodenitis.

The mean age of the patients was 42.03 years (1889 years). Ninety-eight (42.4\%) patients were male, one hundred thirty-three $(57.6 \%)$ patients were female (Table 1).

The most common symptoms/findings in the preendoscopic evaluation of patients were dyspepsia $(45.02 \%)$, chronic diarrhea $(38.10 \%)$, and iron deficiency anemia (34.20\%) respectively (Table 1 ).

According to the histopathological results of biopsies (primary and secondary) with duodenitis in our study, the two most common diagnoses were NSD and CD. NSD was detected in 135 (58.44\%) patients. The second most common cause of duodenitis was CD, which was seen in $69(29.87 \%)$ patients and was the most common cause of secondary duodenitis. All histopathological diagnoses are summarized in Figure 1. 


\begin{tabular}{|c|c|c|}
\hline \multicolumn{3}{|c|}{$\begin{array}{l}\text { Table 1. Demographic characteristics of patients and endoscopi } \\
\text { procedure indications }\end{array}$} \\
\hline \multirow{3}{*}{ Age (years) } & All patients (mean \pm SD) & $42.03 \pm 13.9(18-89)$ \\
\hline & Male (mean $\pm S D)$ & $41.14 \pm 11.8(19-82)$ \\
\hline & Female (mean \pm SD) & $42.89 \pm 15.7(18-89)$ \\
\hline \multirow{2}{*}{ Gender (n, \%) } & Male & $98(42.4 \%)$ \\
\hline & Female & $133(57.6 \%)$ \\
\hline \multirow{6}{*}{$\begin{array}{l}\text { Endoscopic } \\
\text { procedure } \\
\text { indications } \\
\text { (complaints and } \\
\text { findings) (n, \%) }\end{array}$} & Dyspepsia & $104(45.02 \%)$ \\
\hline & Chronic diarrhea & $88(38.10 \%)$ \\
\hline & Iron deficiency anemia & 79 (34.20\%) \\
\hline & Vitamin B12 deficiency & $44(19.05 \%)$ \\
\hline & Abnormal weight loss & $42(18.18 \%)$ \\
\hline & Gastrointestinal bleeding & $24(10.39 \%)$ \\
\hline
\end{tabular}

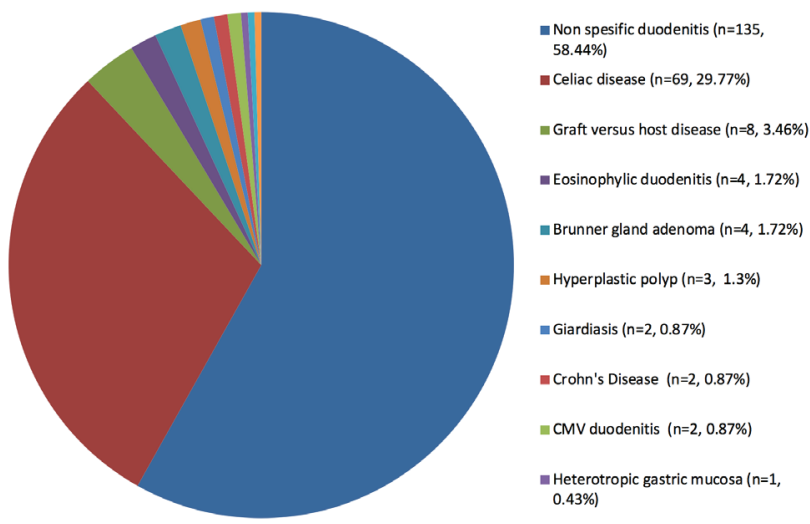

Figure 1. Histopathological results of endoscopic biopsies with a preliminary diagnosis of duodenitis (primary: Non-specific duodenitis, secondary: Other diseases) ( $n, \%)$

The mean age of 69 patients whose histopathological results were compatible with CD was 29.66 years (1856). The female/male ratio of those patients was 2.83 . According to the modified MARSH classification, 8 (11.6\%) patients were Marsh I, 19 (27.5\%) patients Marsh IIla, 32 (46.4\%) patients Marsh IIIb, 10 (14.5\%) patients Marsh IIIc.

\section{Discussion}

Chronic duodenitis occurs with long-term epithelial damage and inflammation of the duodenal mucosa and is diagnosed endoscopically and histopathologically. In duodenal biopsies taken with UGE examinations, many different diagnoses can be revealed under the title of chronic secondary duodenitis $(1,2,11)$. Various systemic and gastrointestinal system (GIS) diseases are localized in the small intestine and these diagnoses are reached by endoscopic biopsies. However, although taking biopsies from normal mucosal areas is not recommended according to some study results, there are studies showing that especially in the diagnosis of iron deficiency anemia, duodenal biopsies taken from non-lesional normal mucosa can be useful in reaching a diagnosis, even to a small extent (12-15). We examined the results of biopsies taken from mucosal areas that had abnormal endoscopic findings and reported as duodenitis. Most of the patients who had the endoscopical pre-diagnosis of duodenitis and underwent duodenal biopsy had a history of malabsorption, diarrhea, and anemia (16). The most common symptoms/findings in our patients who underwent biopsy with the prediagnosis of duodenitis were dyspepsia, anemia, and chronic diarrhea (Table 1). It was confirmed that $58.44 \%$ of the duodenal mucosal anomalies that were reported as duodenitis were histopathologically NSD (Figure 1).

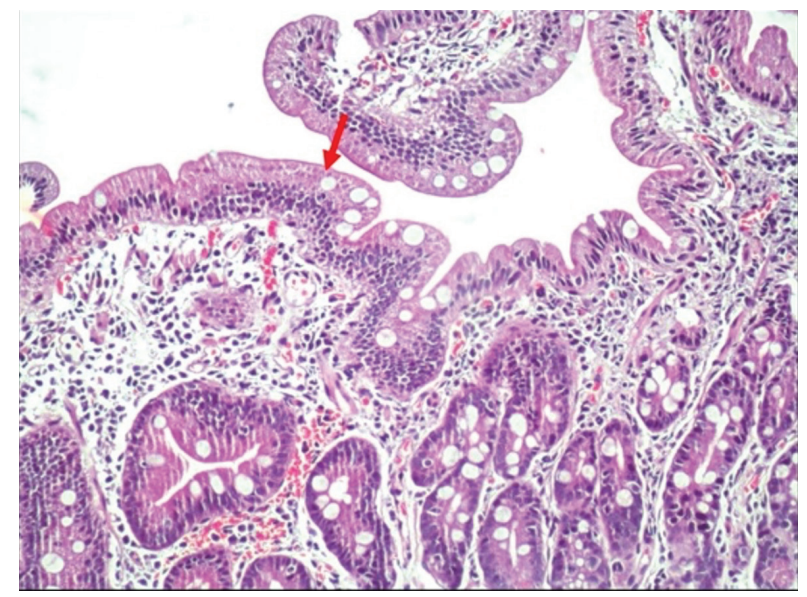

Figure 2. Non-specific duodenitis: Moderate villous blunting and mildly increased lymphocytic inflammatory cell invasion and congestion in lamina propria (H\&E, 200X)

H\&E: Hematoxylin and Eosin

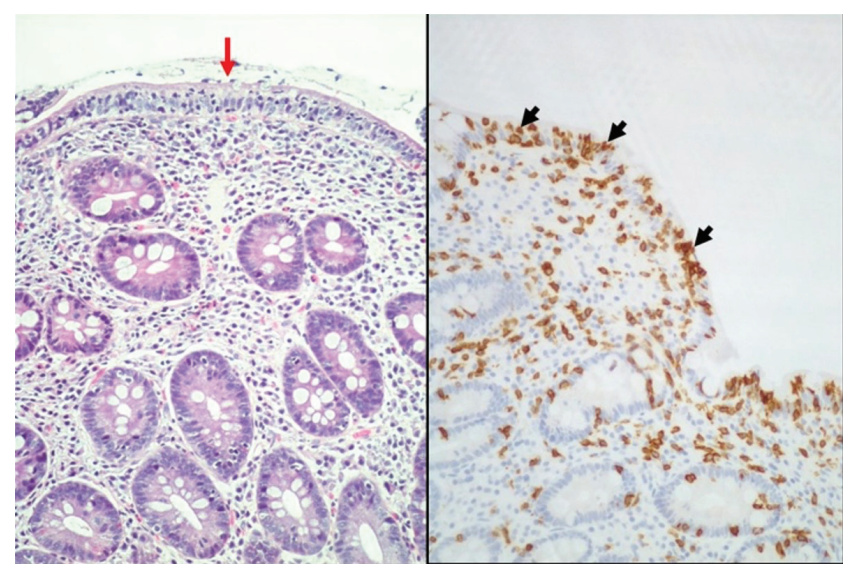

Figure 3. Celiac Disease: a-Complete villous atrophy in a duodenal biopsy of a patient with Celiac Disease (red arrows), (H\&E, 200 X). b- Intraepithelial lymphocytosis highlighted with anti-CD3 immunohistochemistry (black arrowheads), (anti-CD3 immunohistochemical antibody, 200X)

H\&E: Hematoxylin and Eosin 


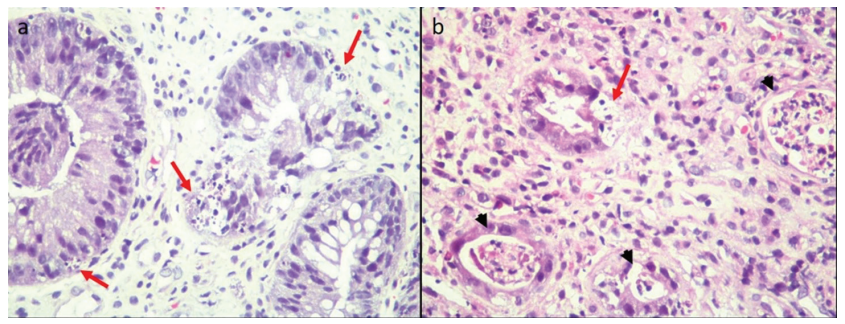

Figure 4. Graft versus host disease (GvHD): a- Apoptotic changes in colonic crypt epithelium, (red arrows, H\&E, 400X). b-Prominent crypt denudation and apoptotic crypt abscess, (black arrowheads), (H\&E, 200X)

H\&E: Hematoxylin and Eosin

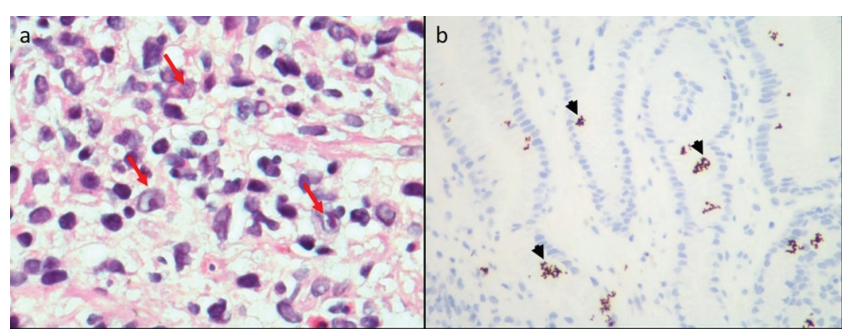

Figure 5. Cytomegalovirus (CMV): a-Nucleomegaly and basophilic intranuclear inclusions in vascular endothelial cells, (red arrows), (H\&E, 1000X). b- Positive reaction with anti-CMV immunohistochemical antibody, (black arrowheads), (anti-CMV antibody, 400X)

H\&E: Hematoxylin and Eosin

Several microscopic images of duodenitis cases belonging to our patients are shown in Figures 1-5.

The most common secondary histopathological duodenitis etiology was $C D$, which is a global disease. The prevalence of $C D$ in the general population is about 0.5 $\%$ to $1 \%$. According to the histopathological results of our patients who underwent biopsies with a preliminary diagnosis of duodenitis, CD was the most common secondary cause of duodenitis with $29.87 \%$ and was the second most common cause in all cases with duodenitis (primary and secondary) (Figure 1). The incidence of CD may be partially related to better recognition of the disease, more testing opportunities, and an increase in immune-mediated diseases $(17,18)$. It has been reported that the prevalence of $C D$ has increased approximately 4 times in the last 3 decades. When the literature is examined, it is stated that CD can be diagnosed at a younger age thanks to the advanced endoscopic and clinical facilities but many cases have been reported in advanced ages and most of the patients were female. A striking result from our study was that for $C D$, younger mean age and female gender were predominant (19). In $C D$, in many patients, the first complaint in presentation is dyspepsia. It is an immune-mediated enteropathy that develops in genetically susceptible individuals. In $C D$, the antibodies are formed mainly against gluten in wheat and other gluten-like cereal proteins in cereals such as barley, rye, and oats (20-26). Endoscopic findings suggestive of $C D$ include disappearance or decrease in the number of duodenal plicae, combing findings, nodular mucosal appearance with the mosaic pattern but the sensitivity and specificity of these endoscopic findings vary between $59-94 \%$ and $92-100 \%$, respectively. Similar endoscopic findings can also be seen in giardiasis, autoimmune enteropathy, and HIV infection, so histopathology remains the gold standard in diagnosing $C D$. In order to make an accurate histopathological diagnosis of chronic duodenitis, the pathologists should evaluate certain histopathological criteria such as villus to crypt ratio, crypt hyperplasia, damaged/flattened enterocytes, the number of intraepithelial lymphocytes, and ruling out the presence of microorganisms such as Giardia and CMV $(27,28)$. When the endoscopic reports were examined, the number of cases in which the gastroenterologist specified $C D$ as the second preliminary diagnosis besides duodenitis was 63, and in this context, the rate of predicting CD by the endoscopist was $91.3 \%$. This rate is somewhat higher than that of in similar studies in the literature (16). Modified MARSH classification is used in histopathological diagnosis. If there is a clinical suspicion, even if the endoscopist sees a normal-appearing mucosa in the duodenum, taking multiple biopsies from many areas is recommended (14,29-32).

Aside from these two predominant etiologies (NSD and $(D)$, many secondary chronic duodenitis causes such as graft versus host disease (GvHD), Crohn's disease, giardiasis, eosinophilic duodenitis, and CMV duodenitis were also detected (Figure 1). In a study conducted by Han et al. (8) in which 6334 patients' UGE were examined; 475 cases of duodenitis were detected. Twenty-one $(4.4 \%)$ patients were diagnosed with secondary duodenitis, histopathologically. The most common diagnoses of secondary duodenitis were IBD in 7 patients, CMV duodenitis in 3 patients. These two major etiologies were followed by Behcet's disease in 2 patients, radiation-induced duodenitis, Henoch-Schönlein purpura, candidiasis, tuberculous enteritis, eosinophilic enteritis, and parasitic infestation respectively (8).

GvHD is a disease that often involves the skin, liver, and GIS, presenting with organ dysfunction due to a severe immunological reaction caused by T-lymphocytes passing from the donor to the recipient patient $(33,34)$. The risk of developing chronic GVHD within two years after allogeneic bone marrow transplantation is $50-60 \%$. The diagnosis of GVHD is made by endoscopic examination and the histopathological interpretation of the endoscopic mucosal biopsies $(35,36)$. In the hematology clinic of our hospital, bone marrow transplantations are frequently 
performed and $3.46 \%$ of our biopsies with a pre-diagnosis of duodenitis were diagnosed as GvHD (Figure 4). The average age of our patients was 32 years, and the female/ male ratio was 1.66 .

Eosinophilic gastroenteritis (EG) is a disease whose pathogenesis is not fully understood, involving genetic and environmental factors, and is associated with allergy and food hypersensitivity. Eosinophilic duodenitis and gastritis are characterized by persistent symptoms and elevated eosinophil leucocytes in the GIS (37). In a study conducted with 220 cases diagnosed with EG, gastric involvement was the most common (43\%). Duodenal involvement was reported at a rate of $31 \%$. In the present study, EG was determined to be the fourth most common secondary duodenitis etiology with a ratio of $1.72 \%$ (38-40).

Brunner's gland adenoma is a rare benign duodenal neoplasia that occurs as a result of hyperplasia of exocrine glands in the proximal duodenal mucosa. It constitutes $10.6 \%$ of benign tumors of the duodenum and is usually asymptomatic $(41,42)$. In the present study, it was detected at a rate of $1.72 \%$.

In the present study, 2 female patients with 22 and 35 years of age were diagnosed with Crohn's disease by duodenal biopsy. Although duodenal involvement is common in IBD compared to the general population, the low rate of $\mathrm{H}$. pylori infection in these patients is remarkable. Granulomatous inflammation is rarely seen in Crohn's patients with duodenal involvement, and the patients are generally asymptomatic. Therefore, the diagnosis might be challenging. Crohn's disease should be kept in mind in patients with $\mathrm{H}$. pylori negative duodenitis $(8,43,44)$.

CMV causes reinfection by reactivation, especially in immunocompromised hosts, which becomes latent after the primary infection. CMV often involves the GIS. Colonic involvement is the most common. Duodenal involvement is rare. Demonstrating inclusions specific to CMV histopathologically is the gold standard in diagnosis. Performing immunohistochemical staining on tissue samples aids in diagnosis. In our case, we both demonstrated the inclusion bodies and immunohistochemical reaction in detecting CMV duodenitis (Figure 5) $(45,46)$.

Polypoid lesions in the duodenum are rare. Hyperplastic polyps are more common in the duodenum, with a prevalence of $\leq 0.5 \%$. Tubular adenomas are also extremely rare in the duodenum. In a study investigating 25.000 EGD procedures, the incidence of duodenal adenomas was found to be $0.4 \%$ (47). In another study, the incidence of duodenal adenomas was demonstrated to be $0.03 \%$ (48). Sometimes endoscopic polypoid appearing lesions do not represent actual polyps. In a study investigating 19560 endoscopic procedures, 5 duodenal polypoid lesions were detected, all located in the second part of the duodenum, and histopathologically reported as NSD $(49,50)$. In our study, 3 hyperplastic polyps and 1 tubular adenoma without high-grade dysplasia were detected.

Giardia duodenalis (lamblia, intestinalis) is an acute and chronic protozoal infection. It can cause sporadic or epidemic diarrhea, usually in children and young adults who travel internationally and who are immunocompromised. In the chronic form, vitamin, protein, and energy malnutrition can be seen due to malabsorption. The diagnosis of the disease can easily be made by the detection of cysts or trophozoites in the stool. The presence of protozoa in the duodenal aspirate or biopsy also leads to a definitive diagnosis (51). In the present study, we detected Giardia infection in two patients.

Congenital remnants of the gastric mucosa can be seen in any part of the gastrointestinal tract (esophagus, duodenum, ileum, such as Meckel's diverticulum). This condition is called heterotopic gastric mucosa (HGM). It is usually asymptomatic and diagnosed incidentally. In one study, duodenal HGM was reported in $8.9 \%$ of 28.210 patients who underwent endoscopic procedure. In another study, the incidence of HGM was found to be $0.43 \%$. HGM should be histologically differentiated from gastric metaplasias since the latter is an acquired disease that presents following duodenal ulcer and duodenitis. In gastric metaplasia, an incomplete form of gastric tissue is observed in the duodenum which is composed of either foveolar epithelium or pyloric glands only $(52,53)$.

GIS involvement in systemic amyloidosis is frequent. It can involve all parts of the GIS. In autopsy studies, the amyloid accumulation rate in the GIS is $70-100 \%$. In a study conducted in our country, amyloid deposits were also found in the duodenum in all 14 patients diagnosed with amyloidosis in the kidney $(54,55)$. In the present study, amyloid accumulation was demonstrated by Congo red stain in the duodenal biopsy of one patient with the Familial Mediterranean Fever that presented with signs of chronic diarrhea and malabsorption.

\section{Study Limitations}

The number of patients who underwent duodenal biopsy in our study was relatively small and our study was retrospective. We think that these situations create limitations for our study. In the future, multicenter and prospective studies conducted with a larger number of patients will yield more valuable results.

However, in a substantial number of our patients, we identified rare causes of secondary duodenitis. The rare causes of secondary duodenitis are not well known to clinicians, so our study may contribute in this aspect. Similarly, we have seen that similar studies have not been 
conducted in the literature recently. For this reason, we think that the results of our study will contribute to the literature.

\section{Conclusion}

We examined the secondary causes of the lesions endoscopically defined as duodenitis. A sparse number of studies about this topic are present in the literature. In the present study we determined considerable number and variety of causes of secondary duodenitis. In the presence of malabsorption symptoms such as anemia and diarrhea in patients with younger age and female gender, causes of secondary duodenitis such as CD and IBD may be considered. GVHD should be included in the differential diagnosis in the presence of sudden-onset diarrhea in patients with allogeneic bone marrow transplantation.

\section{Authorship Contributions}

Concept: A.B., Design: A.B., U.P.H., Data Collection or Processing: A.B., U.P.H., Analysis or Interpretation: A.B., Literature Search: A.B., U.P.H., Writing: A.B., U.P.H.

Conflict of Interest: No conflict of interest was declared by the authors.

Financial Disclosure: The authors declared that this study received no financial support.

\section{References}

1. Destek S, Gül VO. Nonspesifik Duodenitin Gastrit ve Helikobakter Pilori ile Illişkisi. ACU Sağlık Bil Derg 2020;11:5059.

2. Konorev MR, Litviakov AM, Matveenko ME, Krylov IuV, Kovalev AV, Riashchikov AA. Principles of current classification of duodenitis. Klin Med (Mosk) 2003;81:15-20.

3. Samra H, Mostafa M. Small intestine \& ampulla inflammatory disorders, peptic duodenitis. Pathology Outlines 2020.

4. Taş A, Koklu S, Beyazit Y, et al. The endoscopic course of scattered white spots in the descending duodenum: a prospective study. Gastroenterol Hepatol 2012;35:57-64.

5. Wang CX, Liu LJ, Guan J, Zhao XL. Ultrastructural changes in nonspecific duodenitis. World J Gastroenterol 2005;11:686-9.

6. Suzuki H, Franceschi F, Nishizawa T, Gasbarrini A. Extragastric manifestations of Helicobacter pylori infection. Helicobacter 2011;16:65-9.

7. Voutilainen $M$, Juhola $M$, Färkkilä $M$, Sipponen P. Gastric metaplasia and chronic inflammation at the duodenal bulb mucosa. Dig Liver Dis 2003;35:94-8.

8. Han $Y$, Jung HK, Chang JY, et al. Identification of distinctive clinical significance in hospitalized patients with endoscopic duodenal mucosal lesions. Korean J Intern Med 2017;32:82735.

9. MM Walker, NJ Talley. Duodenitis. In Encyclopedia of Gastroenterology, 2004.
10. Oberhuber G, Granditsch G, Vogelsang H. The histopathology of coeliac disease: time for a standardized report scheme for pathologists. Eur J Gastroenterol Hepatol 1999;11:1185-94.

11. Mirbagheri SA, Khajavirad N, Rakhshani N, Ostovaneh MR, Hoseini SM, Hoseini V. Impact of Helicobacter pylori infection and microscopic duodenal histopathological changes on clinical symptoms of patients with functional dyspepsia. Dig Dis Sci 2012;57:967-72.

12. Tischendorf JJ, Wopp K, Streetz KL, et al. The value of duodenal biopsy within routine upper endoscopy: a prospective study in 1000 patients. Z Gastroenterol 2008;46:771-5.

13. Gonen C, Yilmaz N, Yalcin M, Simsek I, Gonen O. Diagnostic yield of routine duodenal biopsies in iron deficiency anaemia: a study from Western Anatolia. Eur J Gastroenterol Hepatol 2007; 19:37-41.

14. Dickey W, Hughes D. Prevalance of celiac disease and its endoscopic markers among patients having routine upper gastrointestinal endoscopy. Am J Gastroenterol 1999;94:2182-6.

15. Broide E, Matalon S, Kriger-Sharabi O, Richter V, Shirin H, Leshno M. Cost- effectiveness of routine duodenal biopsies in iron deficiency anemia. World J Gastroenterol 2016;22:7813-23.

16. Carmack SW, Genta RM. The diagnostic value of the duodenal biopsy: a clinico-pathologic analysis of 28,000 patients. Dig Liver Dis 2010;42:485-9.

17. Lebwohl B, Rubio-Tapia AR. Epidemiology, Presentation, and Diagnosis of Celiac Disease. Gastroenterology 2021;160:6375.

18. Posner EB, Haseeb M. Celiac Disease. Stat Pearls Publishing; 2021.

19. Farrel RJ, Kelly CP. Celiac Sprue. N Engl J Med 2002;346:1808.

20. Boğa S, Köksal AR, Alkım H, et al. Atipik şikayetlerin endoskopi ile aydınlatılması: çölyak hastalığı. Endoskopi 2016;24:4-8.

21. Catassi C, Kryszak D, Bhatti B, et al. Natural history of celiac disease autoimmunity in a US cohort followed since 1974. Ann Med 2010;42:530-8.

22. Ciacci C, Cirillo M, Sollazzo R, Savino G, Sabbatini F, Mazzacca G. Gender and clinical presentation in adult celiac disease. Scand J Gastroenterol 1995;30:1077-81.

23. Corazza GR, Valentini RA, Andreani ML, et al. Subclinical coeliac disease is a frequent cause of iron-deficiency anaemia. Scand J Gastroenterol 1995;30:153-6.

24. Lo W, Sano K, Lebwohl B, Diamond B, Green PH. Changing presentation of adult celiac disease. Dig Dis Sci 2003;48:395-8.

25. Biagi F, Klersy C, Balduzzi D, Corazza GR. Are we not overestimating the prevalence of coeliac disease in the general population? Ann Med 2010;42:557-61.

26. Ramírez-Sánchez AD, Tan IL, Gonera-de Jong BC, Visschedijk MC, Jonkers I, Withoff S. Molecular Biomarkers for Celiac Disease: Past, Present and Future. Int J Mol Sci 2020;21:8528. 
27. Serra S, Jani PA. An approach to duodenal biopsies. J Clin Pathol 2006;59:1133-50.

28. Shah VH, Rotterdam H, Kotler DP, Fasano A, Green PH. All that scallops is not celiac disease. Gastrointest Endosc 2000;51:717-20.

29. Walker MM, Talley NJ. Clinical value of duodenal biopsies beyond the diagnosis of coeliac disease. Pathol Res Pract 2011;207:538-44.

30. Yang JJ, Thanataveerat A, Green PH, Lebwohl B. Costeffectiveness of routine duodenal biopsy analysis for celiac disease during endoscopy for gastroesophageal reflux. Clin Gastroenterol Hepatol 2015;13:1437-43.

31. Savas N, Akbulut S, Saritas U, Koseoglu T. Correlation of clinical and histopathological with endoscopic findings of celiac disease in the Turkish population. Dig Dis Sci 2007;52:1299303.

32. Tuncel F, Alpaslan A. Çölyak hastalığında serolojik, endoskopik ve histopatolojik bulguların karşılaştırılması; tanı için öneriler. Endoskopi 2020;28:107-12.

33. Yakut M, Kırbaş G, Yusifova A, Seven G, Çınar K, Özden A. et al. Retrospective analysis of endoscopic findings in graftversus-host disease of the gastrointestinal tract. Endoscopy 2009;17:14-7. https://doi.org/10.17940/endoskopi.74934

34. Ross WA, Couriel D. Colonic graft-versus-host disease. Curr Opin Gastroenterol 2005;21:64-9.

35. Jacobsohn DA, Vogelsang GB. Acute graft versus host disease. Orphanet J Rare Dis 2007;2:35.

36. Iqbal N, Salzman D, Lazenby AJ, Wilcox CM. Diagnosis of gastrointestinal graft-versus-host disease. Am J Gastroenterol 2000;95:3034-8.

37. Chehade M, Kamboj AP, Atkins D, Gehman LT. Diagnostic Delay in Patients with Eosinophilic Gastritis and/or Duodenitis: A Population-Based Study. J Allergy Clin Immunol Pract 2021;9:2050-9.

38. Kuzu UB, Köksal AŞ. Eozinofilik gastrointestinal hastalıklar. Güncel Gastroenteroloji 2014.

39. Spergel JM, Beausoleil JL, Mascarenhas M, Liacouras CA. The use of skin prick tests and patch tests to identify causative foods in eosinophilic esophagitis. J Allergy Clin Immunol 2002;109:363-8.

40. Weshil BK, Walker WA. The mucosal barrier, IgE mediated gastrointestinal events, and eosinophilic gastroenteritis. Gastroent Clin North Am 1992;21:387-404.

41. Peetz ME, Moseley HS. Brunner's gland hyperplasia. Am Surg 1989;55:474-7.
42. Lee WC, Yang HW, Lee YJ, et al. Brunner's Gland Hyperplasia: Treatment of Severe Diffuse Nodular Hyperplasia Mimicking a Malignancy on Pancreatic-Duodenal Area. J Korean Med Sci 2008;23:540-3.

43. Halme L, Karkkainen $P$, Rautelin $H$, Kosunen TU, Sipponen $P$. High frequency of helicobacter negative gastritis in patients with Crohn's disease. Gut 1996;38:379-83.

44. Halme L, Rautelin H, Leidenius M, Kosunen TU. Inverse correlation between Helicobacter pylori infection and inflammatory bowel disease. J Clin Pathol 1996;49:65-7.

45. Bulur A, Hacısalihoğlu UP, Merhametsiz Ö, Demir ME. Cytomegalovirus Duodenitis in a Renal Transplant Patient Presenting with Signs of Gastrointestinal Bleeding: A Case Report. Med Bull Haseki 2020;58:477-80.

46. Lee KG, Teo SH, Lim C, Loh A, Chidambaram V, Choo J. Severe gastrointestinal cytomegalovirus disease in two patients with renal vasculitis after immunosuppression. Clin Nephrol 2016;86:154-61.

47. Lim CH, Cho YS. Nonampullary duodenal adenoma: Current understanding of its diagnosis, pathogenesis, and clinical management. World J Gastroenterol 2016;22:853-61.

48. Jepsen JM, Persson M, Jakobsen NO, et al. Prospective study of prevalence and endoscopic and histopathologic characteristics of duodenal polyps in patients submitted to upper endoscopy. Scand J Gastroenterol 1994;29:483-7.

49. Rosty C, Buchanan DD, Walters RJ, et al. Hyperplastic polyp of the duodenum: a report of 9 cases with immunohistochemical and molecular findings. Hum Pathol 2011;42:1953-9.

50. Bulur A, Ozdil K, Doganay L, et al. Polypoid lesions detected in the Upper Gastrointestinal Endoscopy; A retrospective analysis in 19560 patients, a single-center study of a five-year experience in Turkey. North Clin Istanb 2021;8:178-85.

51. Büyükgebiz B, Eroğlu Y, Özen E. Duodenal biyopsi ile tanı konulan bir giardiazis olgusu. DEU Tıp Derg 1993;3:52-5.

52. Min YI, Lee BW, Chang YW, Chi HS, Lee JK. The incidence of gastric metaplasia in patients with duodenal ulcer. Korean J Intern Med 1987;2:93-6.

53. Genta RM, Kinsey RS, Singhal A, Suterwala S. Gastric foveolar metaplasia and gastric heterotopia in the duodenum: No evidence of an etiologic role for Helicobacter pylori. Human Pathol 2010;41:1593-600.

54. Cengiz K, Şahan C, Güner E. Amiloidoz ve Gastrointestinal sistem. O.M.Ü. Tıp Dergisi 2000;17:270-6.

55. Canbakan B, Karahisar S, Seçkin S, Oğuz D, Eskioğlu E, Adanalı S. Duodenal biopsy findings in patients with renal amyloidosis. Turk J Gastroenterol 1997;8:185-7. 